\title{
Article
}

\section{Barrier-Free Wheelchair with a Mechanical Transmission}

\author{
Jongseok Lee, Wonhyeong Jeong, Jaeoh Han, Taesu Kim and Sehoon Oh *
}

Mechanical Engineering Department, Chung-Ang University, Seoul 06974, Korea; lgj1774@cau.ac.kr (J.L.); bigbrowh@cau.ac.kr (W.J.); laioh@cau.ac.kr (J.H.); kimts3548@cau.ac.kr (T.K.)

* Correspondence: osh@cau.ac.kr

\section{check for} updates

Citation: Lee, J.; Jeong, W.; Han, J.; Kim, T.; Oh, S. Barrier-Free

Wheelchair with a Mechanical Transmission. Appl. Sci. 2021, 11, 5280. https://doi.org/10.3390/ app11115280

Received: 18 May 2021

Accepted: 4 June 2021

Published: 7 June 2021

Publisher's Note: MDPI stays neutral with regard to jurisdictional claims in published maps and institutional affiliations.

Copyright: (c) 2021 by the authors. Licensee MDPI, Basel, Switzerland. This article is an open access article distributed under the terms and conditions of the Creative Commons Attribution (CC BY) license (https:// creativecommons.org/licenses/by/ $4.0 /)$.

\begin{abstract}
Wheelchairs are an important means of transportation for the elderly and disabled. However, the movement of wheelchairs on long curbs and stairs is restricted. In this study, a wheelchair for climbing stairs was developed based on a mechanical transmission system that rotates the entire driving part through a link structure and an actuator to change the speed. The first mode drives the caterpillar, and the second mode drives the wheels. When driving on flat ground, it uses landing gears and wheels, and when climbing stairs, it uses the caterpillar; accordingly, a stable driving is possible. The stability of the transmission is confirmed through stress analysis. The method used in our study makes it is possible to manufacture lightweight wheelchairs because a single motor drives both the wheel and caterpillar through the transmission system.
\end{abstract}

Keywords: wheelchair; transmission; stairs-climbing

\section{Introduction}

Wheelchairs are widely used around the world to provide mobility to the elderly and disabled [1]. However, the difficulty to access areas with curbs and stairs using a standard electric-powered wheelchair limits the scope of activities, thereby declining the quality of life of those who depend on electric-powered wheelchairs [2]. Although slopes and elevators are being introduced to promote barrier-free locomotion, it is difficult to implement them in all public facilities. Therefore, climbing up and down the stairs is inevitably a critical issue with respect to user safety [3]. With the increasing interest in the aging population and health welfare around the world, various studies on indoor electric wheelchairs for the elderly and disabled are being conducted [4-6].

The recent developments in the field of electric wheelchairs can be categorized into the wheel-type and caterpillar type methods [7]. The representative example of the wheeltype method is iBot. The iBot presents a method of climbing stairs by changing the angle of movement and the center of gravity of the occupant. The other type of method is the caterpillar, which is essentially, a track system. Tracks are often used in military vehicles such as heavy machinery, tanks, and armored vehicles. Because a caterpillar pushes the ground with a wide surface area, the contact pressure is low; therefore, driving in a rough terrain is convenient. However, each type of method has its respective drawbacks. In case of the iBot, owing to the statically unstable two-point grounding of the stairs, the user must hold the railing to maintain balance while climbing the stairs without the assistance of a caregiver [2,8]. The caterpillar is stable while climbing stairs; however, it is unsuitable for driving on level ground.

In this study, the authors attempt to develop a wheelchair that addresses the limitations of the use of only wheels or caterpillars in conventional electric wheelchairs by pro-moving flexibility in the use of wheels on level ground and caterpillars on stairs. Wheelchairs that drive both a caterpillar and a wheel at the same time have already been studied a lot, such as TGR Explorer, TopChair-S and Scewo bro. However, their slightly more complicated structure and higher price partially hinder a more extensive application among the elderly population and persons with disabilities [9]. In the case of Scewo's wheelchair, it is 
equipped with the iBot function, so it is expensive and very heavy at $101 \mathrm{~kg}$. This study aims to reduce the weight and price with a simple structure, so that it can be applied to more disabled people and the elderly. The target weight of the wheelchair is $65 \mathrm{~kg}$ and the weight of the user who can ride it is $100 \mathrm{~kg}$. In addition, it will be possible to provide more convenience by going up and down the stairs alone without the help of a guardian.

In this paper, we designed a transmission and pulley position conversion system to divide the wheelchair into two modes. Through mathematical calculations, the gear specifications of the transmission and the size of the pulley position conversion system are determined. The reliability of the transmission was verified through the stress analysis of the gear, and the drivability, stability, and operability of the wheelchair drive part were verified through the actual production.

\section{Proposed Wheelchair Concept}

Conventionally, electric wheelchairs comprising wheels and caterpillars are extremely heavy because the motors that drive the wheels and caterpillars are separate. In this study, the authors attempt to develop a lightweight electric wheelchair, incorporating both driving wheels and caterpillars in tandem, using a single motor. Figure 1 show a 3D model of an electric wheelchair. On flat ground, the wheelchair is driven by wheels and a landing gear located in front of the wheelchair, and while climbing stairs, it is driven by a caterpillar.

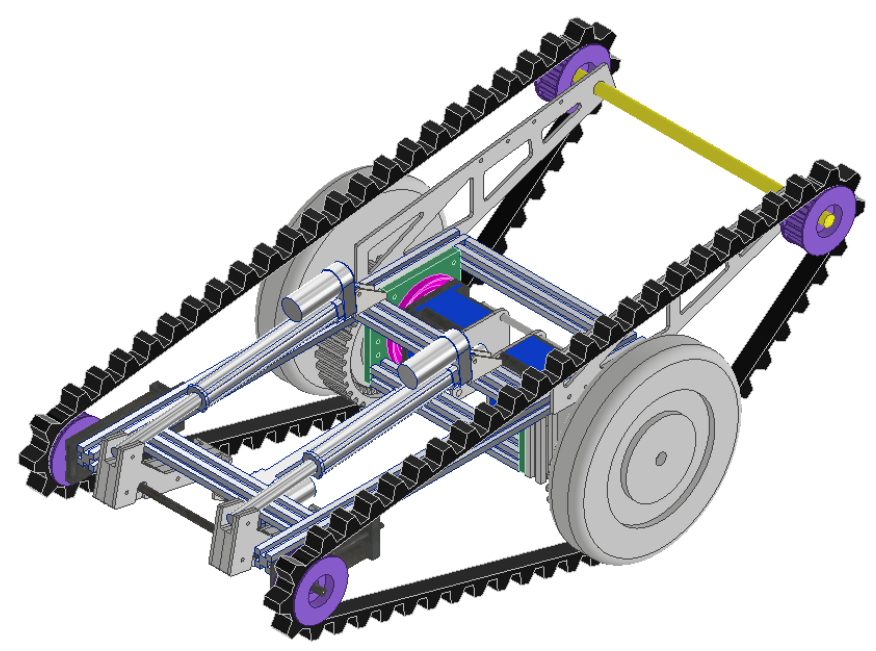

Figure 1. 3D model.

Basically, stairs are climbed by forming an entry angle using the landing gear, and when the front part of the caterpillar hits the first step of the staircase, the landing gear is folded and accordingly, a step of the staircase is climbed using the caterpillar. When one reaches the last step of the staircases, the landing gear is spread to prevent impact on the wheelchair. While descending the stairs, the first step is approached in a similar manner as that while ascending. After folding the landing gear and entering the staircase, the landing gear is spread again, before the center of gravity is completely crossed to prevent impact; thereafter, the landing gear is folded again and accordingly, the user descends the stairs. In the last step after having descended the stairs, the extended caterpillar at the rear of the caterpillar prevents impact.

\section{Transmission System}

Figure 2 is a simplified schematic of the transmission. The transmission consists of a sun-gear shaft and ring gear. The motor is connected to the sun gear, and as the motor power transmits the power to the ring gear through the sun gear, it is decelerated by the number of teeth of the sun gear and ring gear. On the outer surface of the ring gear, a pulley is formed that drives the rubber track. Pulleys and wheels look like they consume a 
lot of power because they are in a state of constant rotation. However, when driving in one mode, the other mode does not consume much power because it is not loaded.

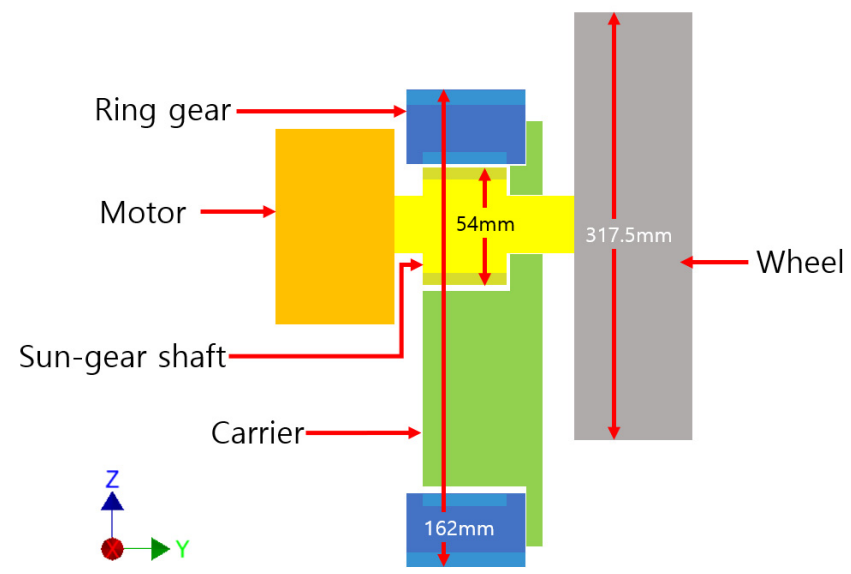

Figure 2. Dual-speed transmission structure drawing.

\section{Specification}

The specifications of the motor used for wheelchairs are shown in Table 1. A geared motor equipped with a reducer is used to lower the speed of the wheelchair and allow for greater torque.

Table 1. Motor specification.

\begin{tabular}{cccc}
\hline & Symbol & Unit & Value \\
\hline Power & $\mathrm{P}$ & $\mathrm{W}$ & 200 \\
Torque & $\mathrm{T}$ & $\mathrm{Nm}$ & 0.65 \\
Speed & $\mathrm{N}$ & $\mathrm{rpm}$ & 3000 \\
Voltage & $\mathrm{V}$ & $\mathrm{V}$ & 24 \\
Current & $\mathrm{I}$ & $\mathrm{A}$ & 13 \\
Reduction ratio & & & 30 \\
Reducer efficiency & $i$ & $\%$ & 86 \\
\hline
\end{tabular}

The maximum speed of an electric wheelchair, as recommended by the Ministry of Food and Drug Safety, must be $15 \mathrm{~km} / \mathrm{h}$ or less [10]. In this study, for the developed indoor electric wheelchair, a flat land speed of $5 \mathrm{~km} / \mathrm{h}$ and a stair climbing speed of $1 \mathrm{~km} / \mathrm{h}$ were ensured.

Figure 3 shows an exploded view and a cross-sectional view of the transmission. Since the gear specifications of the transmission is an important parameter in designing the pulley position conversion system, which is the core of this study, it will be dealt with in detail through mathematical calculations.
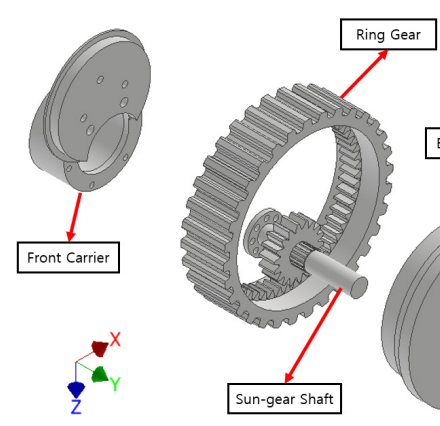

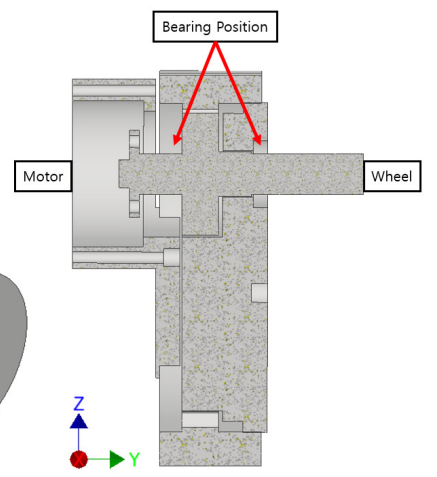

Figure 3. Exploded and cross-sectional view of the dual-speed transmission system. 


\section{Pulley Position Conversion System}

While driving the wheels and caterpillars in tandem, interference between the wheels and caterpillar can occur if the flat-ground driving mode and the stairs-climbing mode are not adequately distinguished. Such a situation can cause vibrations and the problem of directional distortion due to the speed difference between the two wheels, leading to major accidents while moving along staircases. Wheelchair accidents on staircases can be severe and even fatal [1,11]. To prevent this, the position of the driving pulley is changed to allow the wheelchair to be driven by both the caterpillars and wheels.

The following Figure 4 presents an exploded view of the pulley position conversion system. By pushing the motor bracket using a linear actuator, the entire driving part is rotated to change the position of the pulley. The system is structurally capable of moving the pulley at angles of up to $90^{\circ}$. Furthermore, mathematical calculations were performed to clearly separate the wheel driving position and the stair climbing position within a limited displacement.

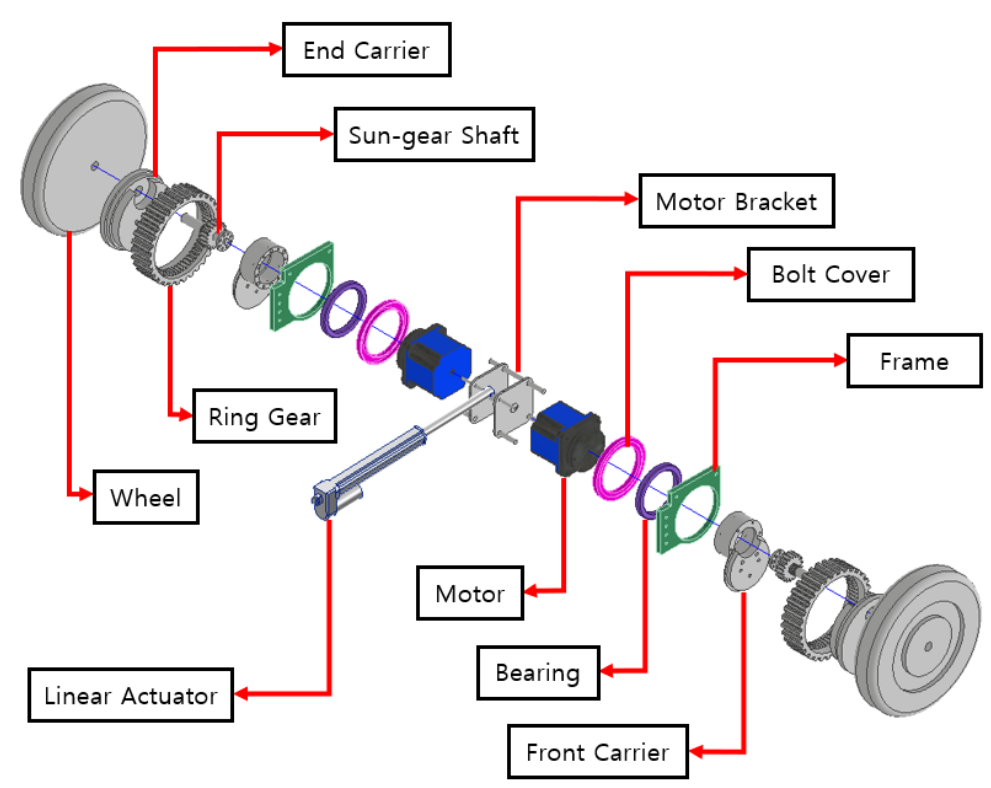

Figure 4. Exploded view of pulley position conversion system.

The linear actuator used in the pulley position conversion system is an electric linear actuator. Specifications are shown in Table 2.

Table 2. Linear actuator specifications.

\begin{tabular}{ccc}
\hline & Unit & Value \\
\hline Voltage & $\mathrm{V}$ & 24 \\
Power & $\mathrm{W}$ & 30 \\
Max load & $\mathrm{N}$ & 1200 \\
Stroke & $\mathrm{mm}$ & 150 \\
Weight & $\mathrm{g}$ & 900 \\
\hline
\end{tabular}

\section{Mathematical Calculation}

The degree of inclination of the electric wheelchair while driving on level ground should be such that the caterpillar is able to climbs the first unit of the staircase. Because a $650-\mathrm{mm}$ caterpillar must be placed on a $20-\mathrm{cm}$ staircase, it must be inclined to an angle greater than $18^{\circ}$. Therefore, the degree of inclination of the landing gear is set to $20^{\circ}$.

The slope of the extended caterpillar that is installed to prevent impact while descending stairs should be $35^{\circ}$ based on the slope of the stairs with a height of $18 \mathrm{~cm}$ and a 
width of $26 \mathrm{~cm}$, as per the stair installation standard. In the calculation, the value of the pulley radius is inclusive of the thickness of the rubber track. For moving on level ground, 317.5-mm wheels were used.

\subsection{Running on Flat Ground}

The motor shaft is the origin and the eccentric angle of the pulley with respect to the vertical axis is denoted by $\theta\left(^{\circ}\right)$. The clockwise direction is considered as positive. When a straight line inclined at $20^{\circ}$, contacts with the pulley and when the vertical distance between the motor shaft and the contact point is less than the wheel radius, it is possible to drive while the wheel is in contact. This is expressed by the following formula.

$$
158.75>r_{1}+e \cos (\theta+20) \quad(0<\theta<90)
$$

$r_{1}$ : Radius of pulley (including rubber orbit)

$e$ : Eccentricity

$\theta$ : Eccentric angle of pulley

In inequality (1), to maximize the distance between the caterpillar and the wheel, the value of ecos $(\theta+20)$ must be minimum. Therefore, the value of $\cos (\theta+20)$ is zero, and $\theta$ is $70^{\circ}$.

$$
158.75>r_{1}
$$

\subsection{Climbing Stairs}

The calculation required to ascend/descend stairs is also centered around the motor shaft, as is the case for movement on flat ground. To ascend the stairs, the caterpillar that extends backward must be at the rear of the wheel. Therefore, the counterclockwise direction of the vertical axis of the origin is considered positive. While climbing stairs, only the caterpillar must touch the stairs; therefore, the distance from the origin to the bottom of the caterpillar must be greater than the radius of the wheel. Furthermore, because the wheel must not touch the ground even when the caterpillar is extended, a tangent line with a slope of $35^{\circ}$ must be drawn such that the distance between the contact point with the pulley and the origin must be greater than the radius of the wheel. This is expressed as follows:

$$
\begin{array}{cc}
158.75<r_{1}+e \cos (35-\theta) & (0<\theta<35) \\
158.75>r_{1}+e \cos (\theta-35) & (35<\theta<90) \\
158.75>r_{1}+e \cos \theta \quad(0<\theta<90)
\end{array}
$$

In inequality (4), to maximize the distance between the caterpillar and the wheel, the value of $e \cos \theta$ must be maximum; therefore, the value of $\cos \theta$ is 1 , and consequently, the value of $\theta$ becomes zero.

$$
\begin{gathered}
158.75<r_{1}+e \cos 35 \quad(0<\theta<35) \\
158.75>r_{1}+e
\end{gathered}
$$

\subsection{Gear Specification}

Because the eccentricity and the center distance of the reducer gear have the same values, the determination of the gear specification is influenced. The module value of the reduction gear was set at three, and the ratio of the number of teeth between the inner and outer gears was set to 3:1. Because the difference between the number of teeth is three-fold, the pitch diameter of the inner gear and that of the outer gear also differ by three times. Accordingly, the relationship between the center distance and the outer gear pitch radius is as follows:

$$
r_{2}=\frac{3}{2} e
$$


$r_{2}$ : Outer gear pitch radius.

When the thickness of the belt is approximately $30 \mathrm{~mm}$, the difference between the radius of the pulley including the belt, and the radius of the pitch circle of the ring gear should be $30 \mathrm{~mm}$ or more. In addition, if the height difference between the caterpillar and the wheel is small in a wheelchair being driven on a flat ground, a situation wherein the caterpillar touches even a small object, may arise. Therefore, it is necessary to determine the solution in which the difference between the wheel and the caterpillar is the maximum while flat driving on flat ground. In other words, it is necessary to determine the value at which the eccentricity becomes the maximum. This can be expressed as the following equation:

$$
158.75-e \cos 35-\frac{3}{2} e>30
$$

Inequality $(2,6,7,9)$ are shown graphically in Figure 5.

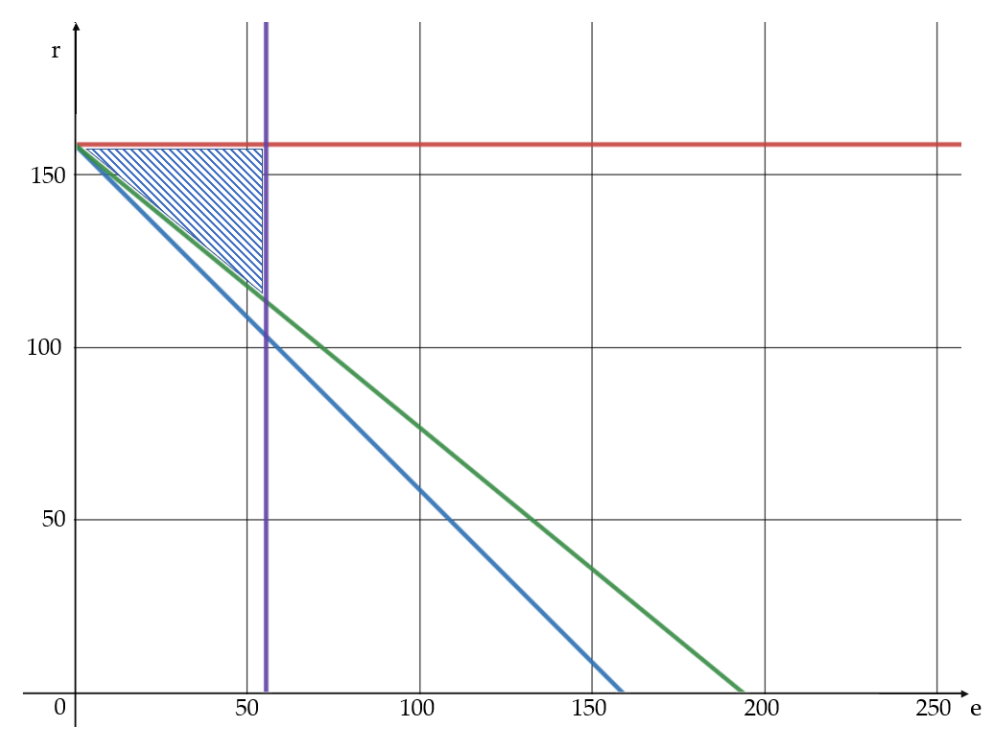

Figure 5. Graph showing the optimization area of eccentricity(e) and radius(r).

The optimized values are in the shaded area in Figure 5. The number of teeth of the gear must be an integer, and therefore it is set to 54, which is the closest multiple of 3 to $55.52 \mathrm{~mm}$. At this time, the radius of the pulley must be $113.5 \mathrm{~mm}$ or more, and the specifications of the transmission and the size of the pulley based on this are presented in Table 3.

Table 3. Transmission specification.

\begin{tabular}{cc}
\hline Specification & Unit $(\mathbf{m m})$ \\
\hline Module & 3 \\
Inner gear pitch circle diameter $(\mathrm{z} 1=18)$ & 54 \\
Outer gear pitch circle diameter $(\mathrm{z} 2=54)$ & 162 \\
Center distance (eccentricity) & 54 \\
Pulley diameter (including belt thickness) & 230 \\
\hline
\end{tabular}

Using the above specifications, the flat land speed and the stair climbing speed of the wheelchair are $5.148 \mathrm{~km} / \mathrm{h}$ and $1.242 \mathrm{~km} / \mathrm{h}$, respectively.

$$
v=r \times \frac{\pi n}{30}
$$

The following Figure 6 shows the positions and sizes of the wheels and pulleys based on the above specifications. 


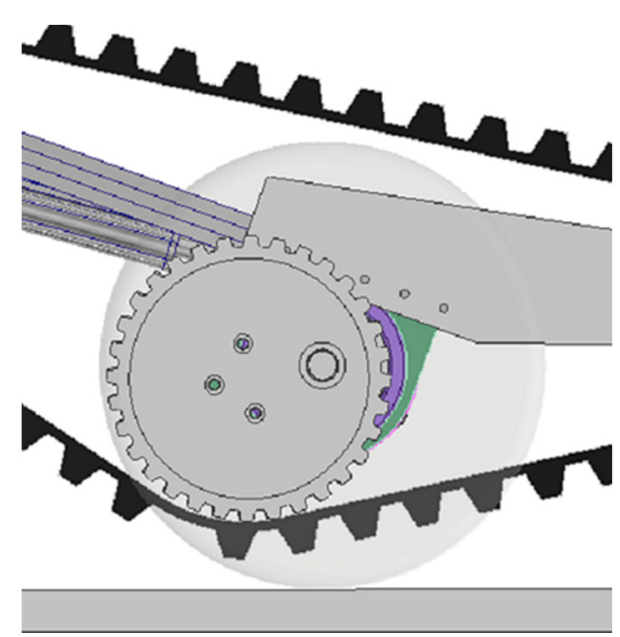

(a) Flat-ground driving mode

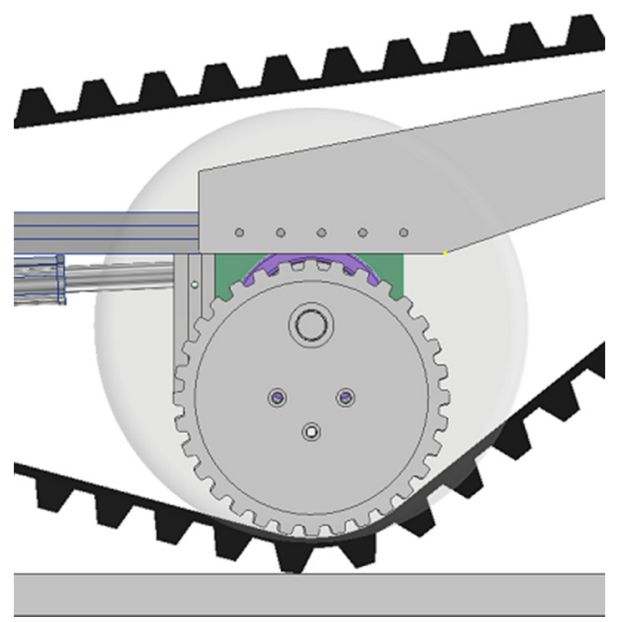

(b) Stair climbing mode

Figure 6. Comparison between flat-ground driving and stair-climbing modes. (a) Flat-ground driving mode. (b) Stair climbing mode.

\subsection{Gear Reference Efficiency}

The gear engagement efficiency was calculated based on the gear specification above. The gear contact ratio was calculated using Equation (10), and the gear reference efficiency was calculated using Equation (13) [12].

$$
\begin{gathered}
\varepsilon=\frac{\sqrt{\left(\frac{d_{k 1}}{2}\right)^{2}-\left(\frac{d_{g 1}}{2}\right)^{2}}-\sqrt{\left(\frac{d_{k 2}}{2}\right)^{2}-\left(\frac{d_{g 2}}{2}\right)^{2}}+a_{x} \sin a_{b}}{\pi m \cos a_{0}} \\
\varepsilon_{1}=\frac{z_{2}}{2 \pi}\left(\tan _{b}-\tan _{k 2}\right) \\
\varepsilon_{2}=\frac{z_{1}}{2 \pi}\left(\operatorname{tana}_{k 1}-\tan _{b}\right) \\
\eta=1-\mu \pi\left(\frac{1}{z_{1}}-\frac{1}{z_{2}}\right)\left(\varepsilon_{1}^{2}+\varepsilon_{2}^{2}+1-\varepsilon_{1}-\varepsilon_{2}\right)(1<\varepsilon<2)
\end{gathered}
$$

$d_{k}$ : Tip diameter

$d_{g}$ : Base diameter

$a_{b}$ : Working pressure angle

$a_{0}$ : Pressure angle

$a_{k}$ : Dimensional pressure angle

$a_{x}$ : Center distance

$\varepsilon$ : Contact ratio

$\eta$ : Reference efficiency

Based on Equations (10) and (11), the contact rate is 1.97 and the reference efficiency is 0.994.

\section{Gear Stress Analysis}

Reliability is evaluated through stress analysis between the internal gear and the external gear of the reducer. Autodesk Inventor's stress analysis program was used for the analysis. The material used for transmission was $\mathrm{SCM} 420 \mathrm{H}$, and the corresponding properties are shown in Table 4 [13]. 
Table 4. SCM420H properties.

\begin{tabular}{cc}
\hline Properties & Value \\
\hline Modulus of elasticity & $190-210 \mathrm{GPa}$ \\
Poisson's ratio & 0.29 \\
Density & $7.7-8.03\left(\times 1000 \mathrm{~kg} / \mathrm{m}^{3}\right)$ \\
Yield strength & $1034 \mathrm{MPa}$ \\
Tensile strength & $1158 \mathrm{MPa}$ \\
\hline
\end{tabular}

Figure 7a shows the geometry used in the analysis. The mesh consists of 63,029 nodes and 38,249 elements, as shown in Figure $7 \mathrm{~b}$.

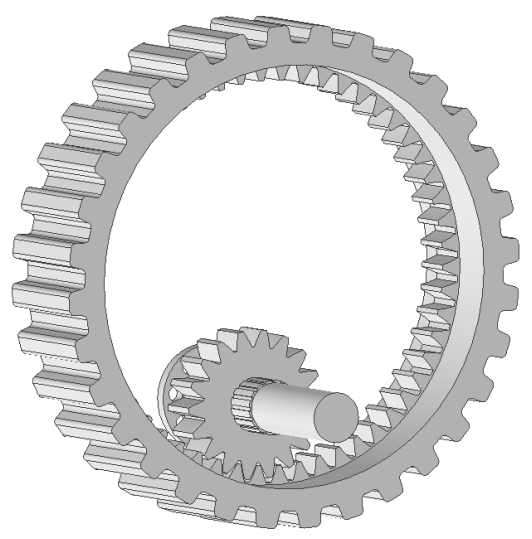

(a) Stress analysis model

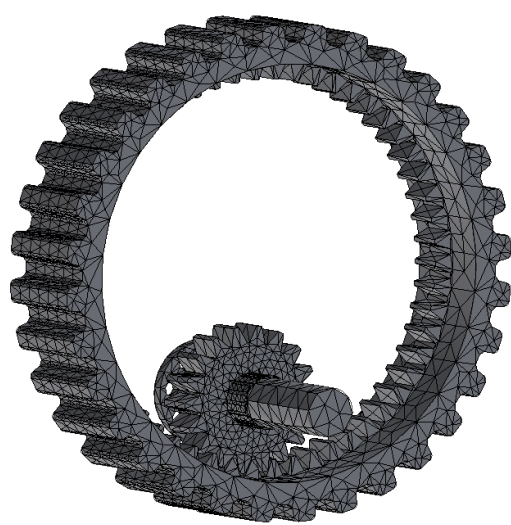

(b) Mesh view

Figure 7. Stress analysis model and mesh view. (a) Stress analysis model. (b) Mesh view.

Figure 8 shows the constraints used in the analysis and the applied force. The sun gear shaft was pinned and a moment according to the motor specifications was applied to the sun gear shaft. The most extreme situation that can be applied to the gear by fixing the outside of the external gear is assumed.



(a) External gear condition

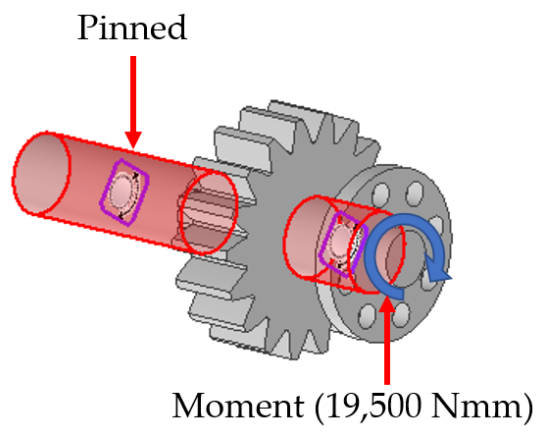

(b) Internal gear shaft condition

Figure 8. Condition of stress analysis. (a) External gear condition. (b) Internal gear shaft condition.

The stress analysis results indicated that the maximum stresses applied to the internal and external gears were $24.45 \mathrm{MPa}$ and $11.45 \mathrm{MPa}$, respectively. This stress analysis was performed by setting extreme conditions that may be applied to the driving part of the wheelchair. It was confirmed that fracture did not occur even under these extreme conditions, which, in turn, validated the stability of the main parts. The results of the stress analysis are shown in Figure 9. 

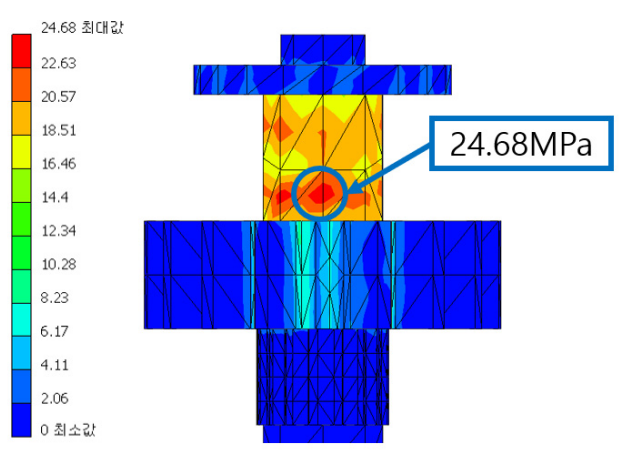

(a) Maximum stress of internal gear shaft

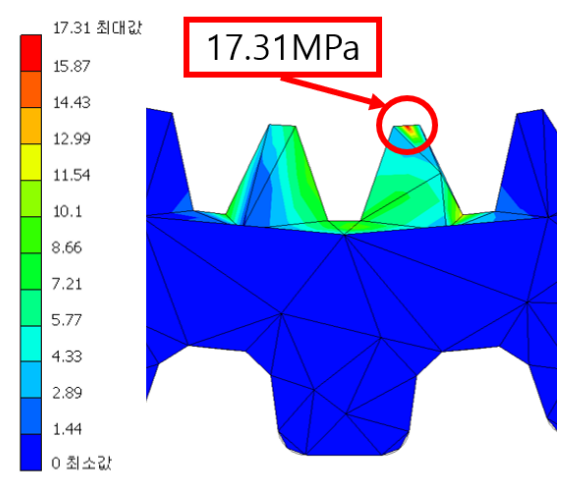

(b) Maximum stress of external gear

Figure 9. Results of stress analysis. (a) Maximum stress of internal gear shaft. (b) Maximum stress of external gear.

\section{Manufacture}

Figure 10 shows an actual manufactured wheelchair. The body was manufactured through aluminum profiles, and the parts were manufactured through laser processing, 3D printing, and cutting processing. The operability was confirmed by testing its ability to climb stairs and move on level ground.

Stair climbing/descending test was conducted as shown in Figure 11. Through this test, the operability of the landing gear and pulley position conversion system was confirmed. In addition, the drivability and stability of the stairs were confirmed. The tested stairs were $15 \mathrm{~cm}$ high and $20 \mathrm{~cm}$ wide, and the weight of the wheelchair was $43 \mathrm{~kg}$.

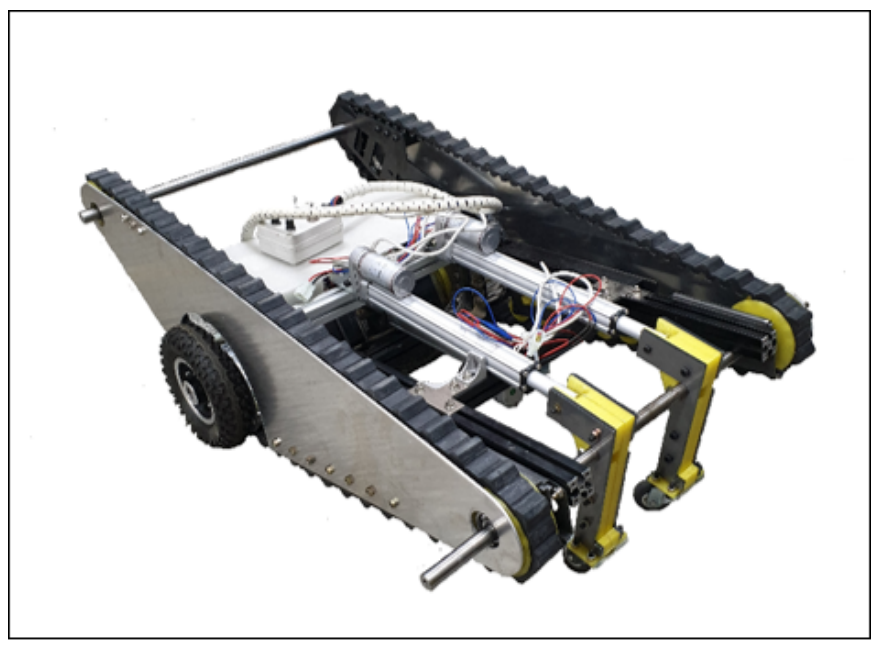

Figure 10. Manufactured wheelchair. 

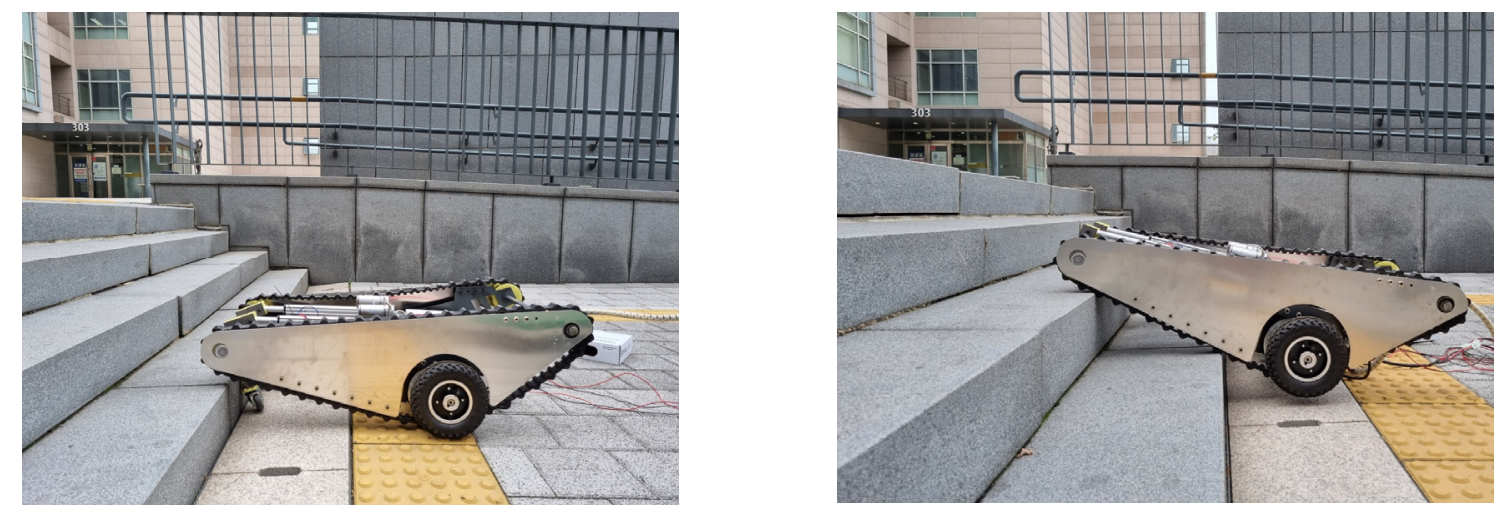

(a) Up-stairs test
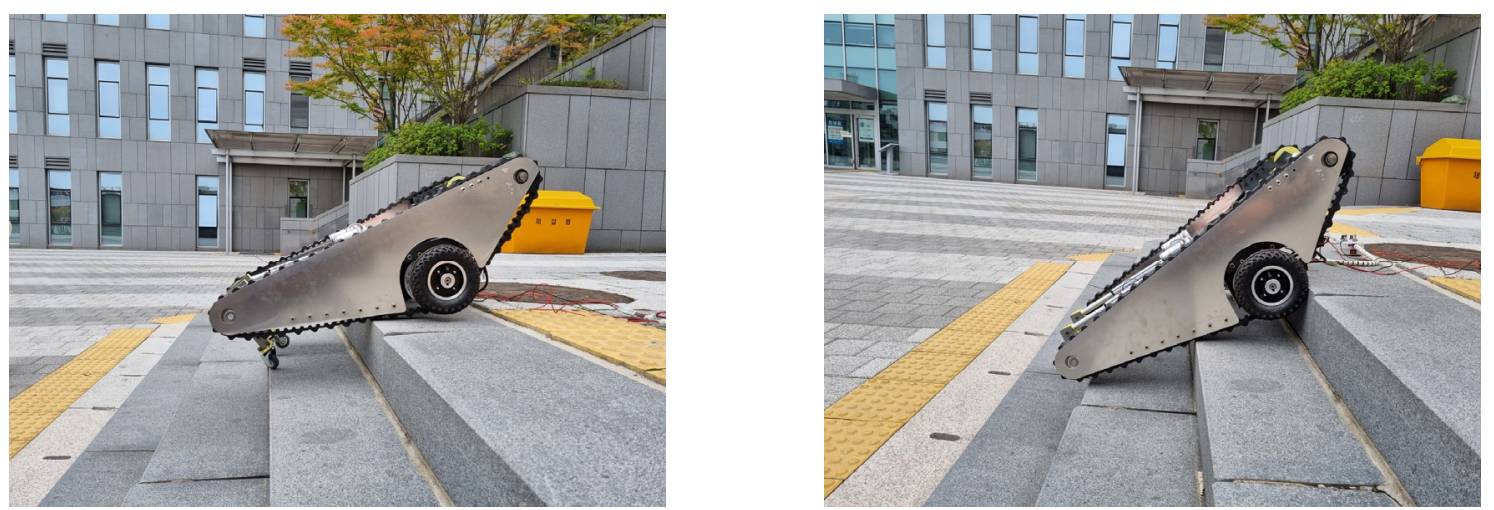

(b) Down-stairs test

Figure 11. Stair test. (a) Up-stairs test. (b) Down-stairs test.

\section{Conclusions}

In this study, an electric wheelchair drive unit capable of climbing stairs and moving on level ground was developed based on a caterpillar and wheel in tandem. Through a 3:1 reducer, comprising a sun gear shaft and ring gear, the caterpillar and wheels were driven at different speeds simultaneously, allowing one to stably ascend/descend stairs. Because driving the caterpillar and wheel simultaneously could cause interference between them, a device that could changes the position of the pulley was incorporated to prevent interference, and the specifications, such as, the pulley angle, pulley radius, and system eccentricity, were calculated to determine the optimum value. The reference efficiency of the gear, was calculated to be 0.994 , and the stability was confirmed through stress analysis. A lightweight electric wheelchair was developed in this study by removing the additional power required to drive the caterpillar and using a single motor to drive both the wheels and caterpillar.

However, this study has certain limitations, particularly in terms of the reliability of the wheelchair in climbing stairs. Unsafe situations arise because we devised a method ascend and descend stairs through only a mechanical mechanism without electronic control. We intend to address this limitation through additional research on climbing and descending stairs more safely through electronic control methods and structural completion. In addition, research on a wheelchair with a chair tilting system through electronic control is also necessary. Since there may be a risk due to a change in the center of gravity when ascending and descending stairs, we aim to devise a chair system that is suitable for this drive system through further research.

This study developed a wheelchair drive unit capable of climbing stairs to provide a barrier-free life to the elderly and the disabled. It is expected that this study can provide a more pleasant environment to the disabled. Furthermore, the proposed driving unit 
presents the possibility of creating more efficient driving units not only for wheelchairs, but also for vehicles that are driven on both rough and flat terrain such as military vehicles, heavy equipment, and unmanned robots.

Author Contributions: Data curation, J.H.; Formal analysis, T.K.; Investigation, W.J.; Software, J.L.; Writing-original draft, J.L.; Writing-review \& editing, S.O. All authors have read and agreed to the published version of the manuscript.

Funding: This research was supported by the Chung-Ang University Graduate Research Scholarship in 2020 .

Institutional Review Board Statement: Not applicable.

Informed Consent Statement: Not applicable.

Data Availability Statement: Not applicable.

Acknowledgments: This work was supported by the Technology Innovation Program (10084565, Development of smart wheelchair power assist module for outdoor activity and off-road drive of the disabled) funded By the Ministry of Trade, Industry \& Energy (MOTIE, Korea).

Conflicts of Interest: The author declares no conflict of interest.

\section{References}

1. Ikeda, H.; Toyama, T.; Maki, D.; Sato, K.; Nakano, E. Cooperative step-climbing strategy using an autonomous wheelchair and a robot. Robot. Auton. Syst. 2020, 135, 103670. [CrossRef]

2. Onozuka, Y.; Tomokuni, N.; Murata, G.; Shino, M. Dynamic Stability Control of Inverted-Pendulum-Type Robotic Wheelchair for Going Up and Down Stairs. In Proceedings of the 2020 IEEE/RSJ International Conference on Intelligent Robots and Systems (IROS), Las Vegas, NV, USA, 24 October-24 January 2021; pp. 4114-4119.

3. Sasaki, K.; Eguchi, Y.; Suzuki, K. Stair-climbing wheelchair with lever propulsion control of rotary legs. Adv. Robot. 2021, 34, 802-813. [CrossRef]

4. Xing, C.; Lee, H.C.; Cho, K.S. The research of disapproval in silver products-testified via electric wheelchair. Sci. Emot. Sensib. 2010, 13, 317-326.

5. Kim, Y.-P.; Ham, H.-J.; Hong, S.-H.; Ko, S.-C. Design and Manufacture of Improved Obstacle-Overcoming type Indoor Moving and Lifting Electric Wheelchair. J. Korea Acad. Ind. Coop. Soc. 2020, 21, 851-860.

6. Song, W.K. Prospects of rehabilitation welfare devices: Based on assistive and robotic devices. J. Rehabil. Welf. Eng. Assist. Technol. 2015, 9, 1-9.

7. Cho, W.; Cho, H.; Kim, J.; Kim, S.; Moon, M. Design of tracked mechanism for stair climbing wheelchair. In Proceedings of the Korean Society of Precision Engineering Conference, Seoul, Korea, 1 June 2011.

8. Uustal, H.; Minkel, J.L. Study of the Independence IBOT 3000 Mobility System: An innovative power mobility device, during use in community environments. Arch. Phys. Med. Rehabil. 2004, 85, 2002-2010. [CrossRef] [PubMed]

9. Tao, W.; Xu, J.; Liu, T. Electric-powered wheelchair with stair-climbing ability. Int. J. Adv. Robot. Syst. 2017, 14, 1729881417721436. [CrossRef]

10. KS P ISO7176-6. Wheelchairs_Part 6: Determination of Maximum Speed of Electric Wheelchairs; ISO/TC 173/SC 1,2. Available online: https:/ / sites.lafayette.edu/wheelchair-team/files/2020/09/Wheelchair_Hill_Assist_Conceptual_Design_Report.pdf (accessed on 3 April 2021).

11. Calder, C.J.; Kirby, R.L. Fatal wheelchair-related accidents in the United States. Am. J. Phys. Med. Rehabil. 1990, 69, 184-190. [CrossRef] [PubMed]

12. KHK Stock Gears. GEAR TECHNICAL REFERENCE. Gear Knowledge. Available online: http://khkgears.net/gear-konwledge/ gear-technical-reference/ (accessed on 3 April 2021).

13. 'Longhai' Steels. Available online: https://www.steelss.com/Carbon-steel/scm420h.html (accessed on 5 April 2021). 